\title{
A newly identified novel variant in the CSF2RA gene in a child with pulmonary alveolar proteinosis: a case report
}

\author{
Adel S. Al-Haidary ${ }^{1 *}$, Wadha Alotaibi ${ }^{1}$, Sami A. Alhaider ${ }^{2}$ and Suhail Al-Saleh ${ }^{3}$
}

\begin{abstract}
Background: The congenital form of pulmonary alveolar proteinosis due to colony stimulating factor 2 receptor alpha gene mutations is a rare disease with only a few cases reported worldwide. In this study we report a new case of pulmonary alveolar proteinosis with a novel variant in colony stimulating factor 2 receptor alpha gene.
\end{abstract}

Case presentation: A 5-year-old Saudi boy presented with a history of progressive dyspnea over 6 months; he was diagnosed as having pulmonary alveolar proteinosis. A molecular study revealed a novel variation in colony stimulating factor 2 receptor alpha gene. His clinical condition showed significant improvement after whole lung lavage.

Conclusions: This case has the typical presentation of congenital pulmonary alveolar proteinosis due to colony stimulating factor 2 receptor alpha defect with a novel variant in this gene likely to be pathogenic.

Keywords: Pulmonary alveolar proteinosis, CSF2RA, Whole lung lavage, Pediatrics, Diffuse lung disease, case report

\section{Background}

Pulmonary alveolar proteinosis (PAP) is a respiratory disease characterized by the accumulation of surfactant within alveoli leading to respiratory distress and hypoxemic respiratory failure in severe cases $[1,2]$. PAP is a very rare disease with an estimated prevalence of 0.1 per 100,000 individuals; in more than $90 \%$ of cases, PAP is an autoimmune disease, less commonly it is of the congenital type [3, 4]. The congenital form of PAP is caused by colony stimulating factor 2 receptor alpha (CSF2RA) gene mutation with only a few cases reported worldwide [5-7]. We report a new pediatric case of PAP with the typical presentation of congenital PAP due to CSF2RA gene defect with a novel variant in this gene and good response to therapeutic whole lung lavage (WLL).

\section{Case presentation}

A 5-year-old Saudi boy presented with exertional dyspnea that progressed over 6 months to dyspnea and hypoxemia at rest. He is the first-born of his parents who were first cousins; he has a healthy 3.5 -year-old

\footnotetext{
* Correspondence: adelsanhan@yahoo.com

${ }^{1}$ Department of Pediatrics, King Fahad Medical City, P.O. Box 59046, Riyadh

11525, Saudi Arabia

Full list of author information is available at the end of the article
}

sister. His past medical and familial history were uneventful. He had a mild cough that sometimes contained whitish sputum. His weight was decreasing. He had no history of fever, chest pain, environmental exposure to causative agents, or drug use. His development was appropriate for his age. A clinical examination revealed respiratory distress (respiratory rate was 55 per minute, the oxygen saturation was $95 \%$ on $5 \mathrm{~L} /$ minute face mask oxygen) with mild degree of clubbing of fingers. His body weight and height were less than third centile: body weight $9.85 \mathrm{~kg}$ and height $97.5 \mathrm{~cm}$. A chest examination revealed decreased air movements bilaterally with crackles.

His complete blood count, urea and electrolytes, immune work up, human immunodeficiency virology (HIV) serology, thyroid function test, and echocardiography were all within normal range. A chest X-ray showed widespread bilateral air-space disease (Fig. 1). Metabolic screening (tandem mass spectrometry, urine gas chromatography-mass spectrometry, serum organic and amino acids) was found to be normal. A chest computed tomographic (CT) scan showed ground-glass opacification and interlobular septal thickening (crazy paving pattern) (Fig. 2). Bronchoalveolar lavage (BAL) appeared milky; it was positive for periodic acid-Schiff 


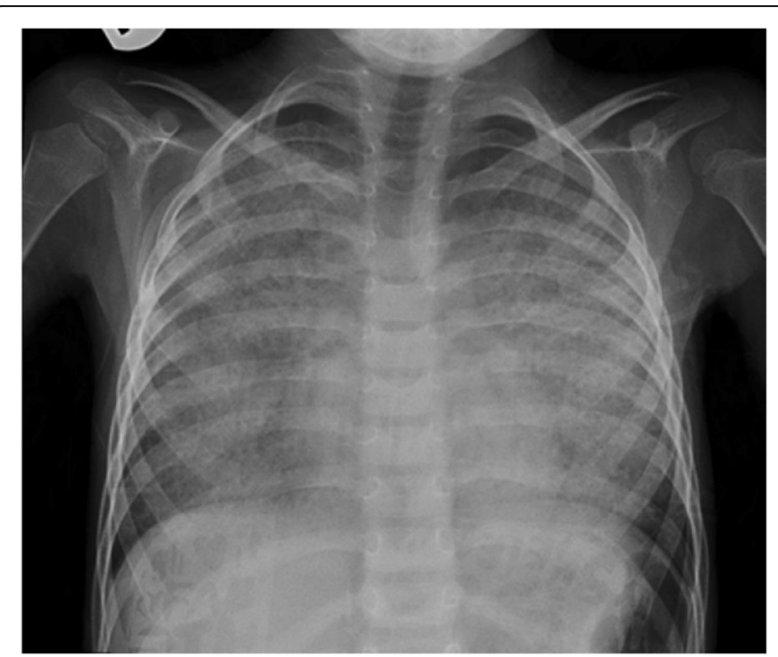

Fig. 1 Chest X-ray showed widespread bilateral air-space disease

(PAS) stain. A molecular genetics study for pulmonary surfactant metabolism dysfunction of seven genes (next-generation sequencing panel for $A B C A 3, C S F 2 R A, C S F 2 R B$, SFTPA1, SFTPB, SFTPC, and SFTPD genes) showed no pathogenic mutation; however, a homozygous novel variant c.533G $>$ A (p.Cys178Tyr) variant was detected in the CSF2RA gene. His serum granulocyte-macrophage colonystimulating factor (GM-CSF) level was high $(15.9 \mathrm{pg} / \mathrm{ml}$, normal level $<7.9 \mathrm{pg} / \mathrm{ml}$ ) and GM-CSF autoantibodies were negative.

Our case was diagnosed as having PAP that was likely to be congenital due to CSF2RA gene mutation so therapeutic WLL was performed. The procedure was performed under general anesthesia; he was intubated using an endotracheal tube of size $5.5 \mathrm{~mm}$. Under

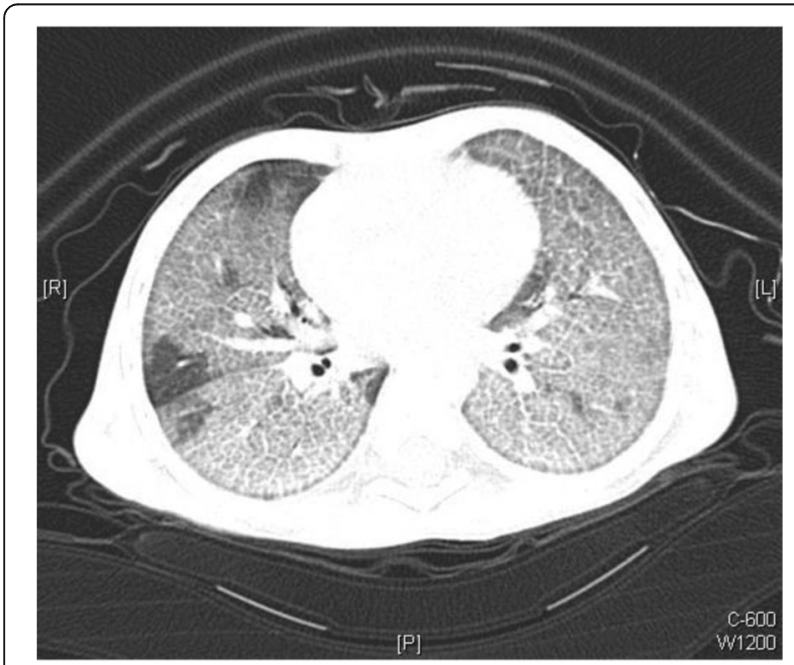

Fig. 2 Computed tomographic scan of the chest showed ground-glass opacification and interlobular septal thickening (crazy paving pattern) fiberoptic bronchoscope (size $2.8 \mathrm{~mm}$ ) direction, a bronchial blocker size 7 French was used to isolate his left lung. A bronchial blocker balloon was inflated and tested for stability and position under direct bronchoscopy observation; no leak was seen upon injecting saline through the catheter. After that, a whole left lung lavage was initiated using body temperature sterile normal saline. We injected $70 \mathrm{~mL}$ of normal saline each time, followed by chest physiotherapy and then aspiration. This procedure was repeated for his right lung. Each lung was washed with a total volume of $2 \mathrm{~L}$ and $40 \mathrm{~mL}$. The left lung revealed $1968 \mathrm{~mL}$ back-aspirate and the right lung revealed $2001 \mathrm{~mL}$ as a total output. The fluid aspirate showed initially white milky fluid with time-dependent sedimentation. The fluid showed sequential progressive clearance toward the end of the procedure. He tolerated the procedure very well, apart from a transient drop in saturation to mid-80s, which responded very well to manual Ambu bagging; his fraction of inspired oxygen $\left(\mathrm{FiO}_{2}\right)$ was kept at 1.0 throughout the procedure. Other than the transient drop in saturation, there was no major complication. He was transferred to our Pediatric Intensive Care Unit, and extubation was successful after 24 hours. After the first WLL his condition gradually showed improvement (respiratory rate was 30 , saturated well on 0.5 to $1 \mathrm{~L} / \mathrm{mi}$ nute nasal cannula oxygen 1 week after WLL), and after 11 months he became symptom-free with normal saturation on room air, with marked radiological improvement (Fig. 3).

Segregation analysis of the family showed that his parents are heterozygous and his 3.5-year-old sister is

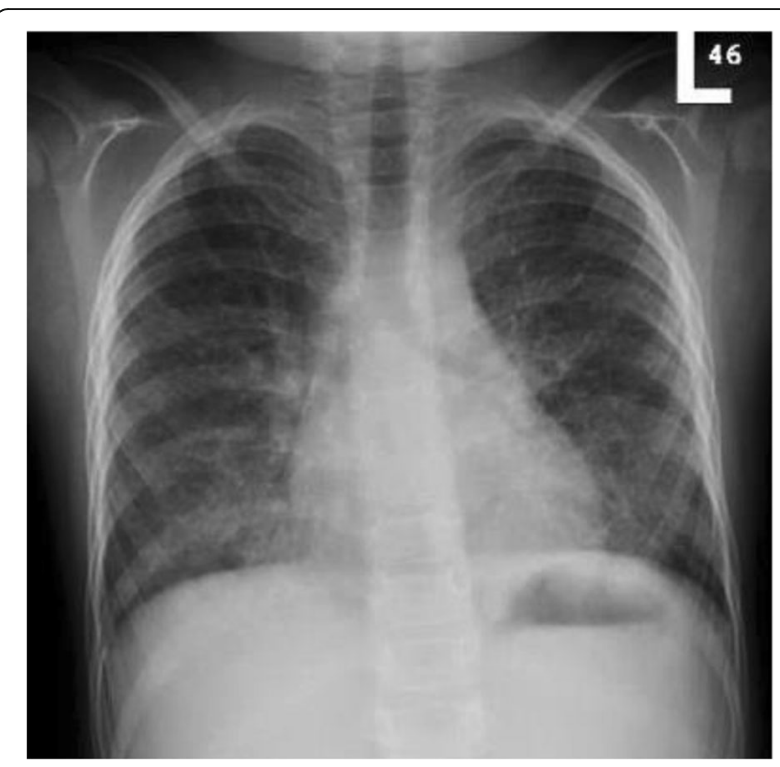

Fig. 3 Chest X-ray 11 months after whole lung lavage with marked radiological improvement 
homozygous for the same mutation. Of interest, his sister is asymptomatic, with unremarkable physical examination findings (oxygen saturation 100\% on room air) with no significant finding on chest X-ray. Currently, she is under regular follow-up and further investigation is postponed because she remains asymptomatic.

\section{Discussion}

The surfactant is a mixture of proteins and lipids secreted by type II pneumocytes, cleared by alveolar macrophages under stimulation of GM-CSF [3]. In adults, the majority of cases of PAP cases autoimmune caused by autoantibodies directed against GM-CSF. Secondary PAP occurred due to impaired macrophage function from hematologic or solid malignancies, toxic dust inhalations, opportunistic infections, lysinuric protein intolerance, immunodeficiency, and immunosuppression agents $[3,4,8]$. In pediatric patients, most cases are of the congenital form and commonly occurred due to mutations in the genes involving surfactant production, that is SFTPB, SFTPC, $A B C A 3$, and thyroid transcription factor $1(N K X 2.1)[1,3,4,9,10]$, or rarely due to mutations in the GM-CSF receptor (CSF2 $\alpha$-chain receptor or CSF2 $\beta$-chain receptor) genes which is responsible for surfactant clearance $[6,7,9]$. Mutations in the genes involved in surfactant production cause PAP with interstitial lung disease, while mutations in the genes for surfactant clearance lead to pure PAP without involvement of interstitial space $[11,12]$.

The clinical presentation of congenital PAP due to CSF2RA defects varies from completely asymptomatic to severe symptoms with respiratory failure $[5,11]$. The CSF2RA gene is found in the pseudoautosomal region 1 (PAR1) of the $\mathrm{X}$ and $\mathrm{Y}$ chromosomes; it is inherited in an autosomal recessive manner [13]. Diagnosis of PAP depends on clinical presentation in addition to the characteristic radiological findings on chest CT scan. Bronchoscopy usually confirms the diagnosis with the findings of typical milky BAL with positive PAS stain $[1,2]$. The majority of cases of congenital PAP due to CSF2RA abnormalities developed progressive dyspnea, exercise intolerance, tachypnea, and hypoxemia at median age of 3.5 years with failure to thrive in $55 \%$ of patients [5]. The GM-CSF level is typically low in patients with autoimmune PAP and elevated in all patients with congenital PAP due to GM-CSF receptor abnormalities $[11,14]$.

Currently, the standard treatment for congenital PAP due to CSF2RA gene mutation is whole lung lavage [5]. All symptomatic patients who received whole lung lavage therapy experienced significant clinical improvement [5]. A single case report described a case with severe initial clinical presentation treated by bone marrow transplantation but the patient died due to respiratory infection 4 weeks after transplant [6]. Other therapeutic trials have been proposed such as pulmonary macrophage transplantation and gene therapy $[15,16]$.

In our case the patient had poor weight gain, progressive dyspnea since the age of 4.5 years with severe respiratory distress, typical radiological finding, his BAL was milky with positive PAS stain, and he had significant improvement after WLL. A novel variant of CSF2RA gene was detected in our case which has a typical clinical presentation for congenital PAP due CSF2RA defect, although this variant needs more work up to approve its pathogenicity.

His 3.5-year-old sister is asymptomatic despite the fact that she has homozygous variant but due to her relatively younger age she may develop symptoms later; as a result, further follow-up is warranted. Of note, clinical presentation of congenital PAP due to CSF $2 R$ defect can be triggered by factors such as respiratory tract infections [17]. Other potential explanations might be related to variation in penetrance, the involvement of modifier gene(s), environmental factors, or epigenetic changes [18].

\section{Conclusions}

Our case has a typical presentation of congenital PAP due to CSF2RA defect, and we identified a novel variant in this gene likely to be pathogenic: c.533G >A (p.Cys178Tyr). Further studies are needed to confirm the pathogenicity of this variant and to characterize its clinical course further.

\section{Abbreviations}

BAL: Bronchoalveolar lavage; CSF2RA: Colony stimulating factor 2 receptor alpha; $\mathrm{CT}$ : Computed tomographic; $\mathrm{FiO}_{2}$ : Fraction of inspired oxygen;

GM-CSF: Granulocyte-macrophage colony-stimulating factor; HIV: Human immunodeficiency virology; PAP: Pulmonary alveolar proteinosis;

PAR1: Pseudoautosomal region 1; PAS: Periodic acid-Schiff stain; WLL: Whole lung lavage

\section{Acknowledgements}

Not applicable.

Funding

None.

Authors' contributions

All authors were involved in the writing and editing of the manuscript. All authors read and approved the final manuscript.

Competing interests

The authors declare that they have no competing interests.

Consent for publication

Written informed consent was obtained from the patient's legal guardian for publication of this case report and any accompanying images. A copy of the written consent is available for review by the Editor-in-Chief of this journal.

Ethics approval and consent to participate

Institutional Review Board (IRB) approved this study. IRB Log Number: 15-151.

\section{Publisher's Note}

Springer Nature remains neutral with regard to jurisdictional claims in published maps and institutional affiliations. 


\section{Author details}

'Department of Pediatrics, King Fahad Medical City, P.O. Box 59046, Riyadh 11525, Saudi Arabia. ${ }^{2}$ Department of Pediatrics, King Faisal Specialist Hospital and Research Centre, Riyadh, Saudi Arabia. ${ }^{3}$ The Hospital for Sick Children, 555 University Avenue, Toronto M5G 1X8, ON, Canada.

Received: 10 November 2016 Accepted: 5 April 2017

Published online: 02 May 2017

\section{References}

1. Trapnell BC, Whitsett JA, Nakata K. Pulmonary alveolar proteinosis. N Engl J Med. 2003;349(26):2527-39

2. de Blic J. Pulmonary alveolar proteinosis in children. Paediatr Respir Rev 2004;5(4):316-22

3. Borie R, Danel C, Debray MP, Taille C, Dombret MC, Aubier M, Epaud R, Crestani B. Pulmonary alveolar proteinosis. Eur Respir Rev. 2011;20(120):98-107.

4. Campo I, Kadija Z, Mariani F, Paracchini E, Rodi G, Mojoli F, Braschi A, Luisetti M. Pulmonary alveolar proteinosis: diagnostic and therapeutic challenges. Multidiscip Respir Med. 2012;7(1):1.

5. Hildebrandt J, Yalcin E, Bresser HG, Cinel G, Gappa M, Haghighi A, Kiper N, Khalilzadeh S, Reiter K, Sayer J, Schwerk N. Characterization of CSF2RA mutation related juvenile pulmonary alveolar proteinosis. Orphanet J Rare Dis. 2014;9(1):1.

6. Martinez-Moczygemba M, Doan ML, Elidemir O, Fan LL, Cheung SW, Lei JT, Moore JP, Tavana G, Lewis LR, Zhu Y, Muzny DM. Pulmonary alveolar proteinosis caused by deletion of the GM-CSFRa gene in the $X$ chromosome pseudoautosomal region 1. J Exp Med. 2008;205(12):2711-6.

7. Suzuki T, Sakagami T, Rubin BK, Nogee LM, Wood RE, Zimmerman SL, Smolarek T, Dishop MK, Wert SE, Whitsett JA, Grabowski G. Familial pulmonary alveolar proteinosis caused by mutations in CSF2RA. J Exp Med. 2008:205(12):2703-10

8. Grunebaum E, Cutz E, Roifman CM. Pulmonary alveolar proteinosis in patients with adenosine deaminase deficiency. J Allergy Clin Immunol. 2012;129(6):1588-93.

9. Suzuki T, Maranda B, Sakagami T, Catellier P, Couture CY, Carey BC, Chalk C, Trapnell BC. Hereditary pulmonary alveolar proteinosis caused by recessive CSF2RB mutations. Eur Respir J. 2011:37(1):201-4.

10. Hamvas A, Deterding RR, Wert SE, White FV, Dishop MK, Alfano DN, Halbower AC, Planer B, Stephan MJ, Uchida DA, Williames LD. Heterogeneous pulmonary phenotypes associated with mutations in the thyroid transcription factor gene NKX2-1. Chest J. 2013;144(3):794-804

11. Suzuki T, Sakagami T, Young LR, Carey BC, Wood RE, Luisetti M, Wert SE, Rubin BK, Kevill K, Chalk C, Whitsett JA. Hereditary pulmonary alveolar proteinosis: pathogenesis, presentation, diagnosis, and therapy. Am J Respir Crit Care Med. 2010;182(10):1292-304

12. Rice A, Tran-Dang MA, Bush A, Nicholson AG. Diffuse lung disease in infancy and childhood: expanding the chILD classification. Histopathology. 2013:63(6):743-55

13. Helena Mangs A, Morris BJ. The human pseudoautosomal region (PAR): origin, function and future. Curr Genomics. 2007:8(2):129-36.

14. Uchida K, Nakata K, Suzuki T, Luisetti M, Watanabe M, Koch DE, Stevens CA, Beck DC, Denson LA, Carey BC, Keicho N. Granulocyte/macrophage-colonystimulating factor autoantibodies and myeloid cell immune functions in healthy subjects. Blood. 2009;113(11):2547-56.

15. Suzuki T, Arumugam P, Sakagami T, Lachmann N, Chalk C, Sallese A, Abe S, Trapnell C, Carey B, Moritz T, Malik P. Pulmonary macrophage transplantation therapy. Nature. 2014;514(7523):450-4.

16. Lachmann N, Happle C, Ackermann M, Lüttge D, Wetzke M, Merkert S, Hetze M, Kensah G, Jara-Avaca M, Mucci A, Skuljec J. Gene correction of human induced pluripotent stem cells repairs the cellular phenotype in pulmonary alveolar proteinosis. Am J Respir Crit Care Med. 2014:189(2):167-82.

17. Santiago-Burruchaga M, Zalacain-Jorge R, Alvarez-Martinez J, ArguinzonizMarzana JM, Pocheville-Guruzeta I, Vazquez-Ronco MA, Gozalo-García A, Vazquez Cordero C. Hereditary pulmonary alveolar proteinosis. Could it be triggered by Mycoplasma pneumoniae pneumonia? Respir Med. 2013;107(1):134-8.

18. Cooper DN, Krawczak M, Polychronakos C, Tyler-Smith C, Kehrer-Sawatzki H. Where genotype is not predictive of phenotype: towards an understanding of the molecular basis of reduced penetrance in human inherited disease. Hum Genet. 2013;132(10):1077-130.

\section{Submit your next manuscript to BioMed Central and we will help you at every step:}

- We accept pre-submission inquiries

- Our selector tool helps you to find the most relevant journal

- We provide round the clock customer support

- Convenient online submission

- Thorough peer review

- Inclusion in PubMed and all major indexing services

- Maximum visibility for your research

Submit your manuscript at www.biomedcentral.com/submit 